Ciência Florestal, Santa Maria, v. 22, n. 3, p. 445-455, jul.-set., 2012 ISSN 0103-9954

\title{
CRESCIMENTO DE MUDAS DE PUPUNHEIRA (Bactris gasipaes Kunth) UTILIZANDO RESÍDUO DE MINERAÇÃO DE AREIA COMO COMPONENTE DE SUBSTRATOS
}

\author{
GROWTH OF PEJIBAYE (Bactris gasipaes Kunth) SEEDLINGS USING RESIDUE OF SAND \\ MINING AS PART OF SUBSTRATES
}

\author{
Valéria Augusta Garcia ${ }^{1}$ Valéria Aparecida Modolo ${ }^{2}$ Ana Maria Magalhães Andrade Lagôa ${ }^{3}$ \\ Maria Luiza Sant'Anna Tucci ${ }^{4}$ Norma de Magalhães Erismann ${ }^{5}$ Domingos Sávio Rodrigues ${ }^{6}$
}

\section{RESUMO}

O objetivo deste trabalho foi avaliar o crescimento de mudas de pupunheira quando utilizado o resíduo fino de mineração de areia na composição de substratos. O experimento constou de cinco tratamentos, sendo quatro composições de diferentes proporções de resíduo de mineração de areia e casca de arroz carbonizada: $1: 0 ; 3: 1 ; 1: 1 ; 1: 3$ e um substrato padrão composto por latossolo amarelo podzólico álico e esterco de búfalo curtido, na proporção 3:1. Utilizou-se o delineamento experimental de blocos ao acaso com cinco repetições e 10 mudas por parcela. Repicou-se uma plântula de pupunheira por recipiente (sacos plásticos de polietileno preto de $8 \times 20 \mathrm{~cm}$, volume $1,1 \mathrm{~L}$ ), os quais foram preenchidos com os diferentes substratos. Foram determinadas mensalmente as variáveis diâmetro do coleto, altura da haste, número de folhas e taxa de crescimento relativo e, após 180 dias da repicagem, os valores SPAD (Soil and Plant Analysis Development), dinâmica da assimilação de $\mathrm{CO}_{2}$, da transpiração e da condutividade estomática. $\mathrm{O}$ resíduo de mineração de areia puro como substrato não proporcionou mudas de qualidade, visto que esse material apresenta alta densidade e baixa granulometria. Seu uso pode ser indicado como um dos componentes de substratos, pois as plantas que cresceram nas misturas de resíduo e casca de arroz carbonizada apresentaram resultados semelhantes ao do considerado padrão.

Palavras-chave: palmito; pupunha; substrato.

\begin{abstract}
The objective of this study was to evaluate the growth of peach palm seedlings using fine residue of sand mining as part of substrates. The experiment comprised five treatments, four containing different ratios of sand mining residue to carbonized rice husk: $1: 0 ; 3: 1 ; 1: 1 ; 1: 3$, and one composed of alic podzolic yellow latosol and buffalo manure in a 3:1 ratio, used as the standard substrate. Treatments were arranged in randomized blocks with five replications and 10 seedlings each. One peach palm seedling was transplanted per container, which consisted of black, $8 \times 20 \mathrm{~cm}, 1.1 \mathrm{~L}$ PE bags filled with different substrates. Diameter of stem, plantlet height, number of leaves and relative growth rate were recorded monthly and 180 days after their transplanting, SPAD values, dynamics of $\mathrm{CO}_{2}$ assimilation, transpiration and stomatal conductance. The use of unmixed residue of sand mining as substrate did not produce quality seedlings, since that substance has high density and poor particle size. It can be used as part of substrates though, for plants

1. Engenheira Agrônoma, Msc., Pesquisadora Científica do Pólo do Vale do Ribeira da Agência Paulista de Tecnologia dos Agronegócios/SAA-SP, Rod. Regis Bittencourt, km 460, Pariquera-açu (SP), Caixa Postal 122, CEP 11900000, Pariquera-açu (SP). valeriagarcia@apta.sp.gov.br

2. Engenheira Agrônoma, $\mathrm{Dr}^{\mathrm{a}}$, Pesquisadora Científica do Instituto Agronômico de Campinas, IAC/APTA, Caixa Postal 28, CEP 13800-000, Campinas (SP). vamodolo@iac.sp.gov.br

3. Bióloga, Dra , Pesquisadora Científica do Instituto Agronômico de Campinas, Caixa Postal 28, CEP 13800-000, Campinas (SP). alagoa@iac.sp.gov.br

4. Engenheira Agrônoma, $\mathrm{Dr}^{\mathrm{a}}$, Pesquisadora Científica do Instituto Agronômico de Campinas, Caixa Postal 28, CEP 13800-000, Campinas (SP). tucci@iac.sp.gov.br

5. Farmacêutica, $\mathrm{Dr}^{\mathrm{a}}$, Pesquisadora Científica do Instituto Agronômico de Campinas, Caixa Postal 28, CEP 13800000, Campinas (SP).normaeri@iac.sp.gov.br

6. Engenheiro Agrônomo, Dr., Pesquisador Científico do Instituto de Botânica/SMA, Av. Miguel Estéfano, 3687, CEP 04301-012, São Paulo (SP). dsrodrigues@ibot.sp.gov.br

Recebido para publicação em 12/03/2009 e aceito em 30/06/2011
\end{abstract}


grown in the mixtures of residue and carbonized rice husk showed similar results to those grown in the standard substrate.

Keywords: heart of palm; peach palm; substrate.

\section{INTRODUÇÃO}

O cultivo da pupunheira (Bactris gasipaes Kunth) com o objetivo de comercializar as hastes de palmito é uma atividade recente tanto no Brasil quanto no mundo. Em países como a Costa Rica, esta atividade foi desenvolvida a partir do final da década de 70 e no Brasil a partir dos anos 90 do século XX. Essa estratégia de produção aliada à rigorosa legislação ambiental de proteção às espécies ameaçadas de extinção e a maior fiscalização sanitária, fez com que a produção de palmito começasse a perder o caráter de atividade extremamente extrativista e se transformasse em um agronegócio viável (BOVI et al., 2002; ABOBOREIRA NETO, 2009). Com o crescente interesse dos consumidores, a participação do palmito cultivado sobre o nativo vem aumentando rapidamente ano a ano. Estima-se que a área de palmito de pupunheira cultivada atualmente no Estado de São Paulo seja superior a 3.900 ha (ANEFALOS et al., 2007), sendo que, na região do litoral sul paulista, denominada Vale do Ribeira, avalia-se que haja mais de 450 produtores se dedicando a produção de palmito de pupunheira, com aproximadamente 11 milhões de pés desta palmeira (LUPA, 2008).

A despeito de trabalhos terem sido realizados sobre alguns aspectos da tecnologia de produção da cultura, como se trata de um cultivo recente, poucos trabalhos científicos foram realizados principalmente quanto às necessidades e problemas relacionados à formação de mudas. Muitas são as dúvidas referentes a substratos, volume de recipiente, adubação e demandas dos nutrientes no decorrer do desenvolvimento da muda. Essa é uma etapa crucial na implantação do cultivo, visto que, no geral, mudas mal formadas e/ou debilitadas podem comprometer o estabelecimento e desenvolvimento em condições de campo, em alguns casos levando à mortalidade de plantas e, por consequência, desuniformidade no estande (MINAMI, 1995; SOUZA e FERREIRA, 1997; PREVITALLI, 2007).

Dentre os fatores importantes a serem avaliados no processo de produção de mudas de boa qualidade, encontram-se os substratos, cuja escolha e correto manejo ainda são um sério problema técnico para os viveiristas (COSTA et al., 2005; BACKES e KAMPF 1991).

Para a produção de mudas, podem ser utilizados substratos de origem mineral ou orgânica, natural ou sintética (GUERRERO e POLO, 1989), não existindo um material ou uma mistura de materiais considerada universalmente válida como substrato para todas as espécies (ABAD, 1991). Para cada espécie e em diferentes situações há a necessidade de avaliar o melhor, ou os melhores substratos, assim como novas alternativas de materiais para sua composição.

Para que um substrato possa ser considerado adequado para produção de mudas é necessário que ele seja um material de fácil disponibilidade, abundante na região onde será utilizado e que apresente características físicas, químicas e biológicas adequadas para o desenvolvimento da espécie em questão. Algumas empresas são geradoras de resíduos que podem poluir o ambiente, mas que, por outro lado, são passíveis de reciclagem. $\mathrm{O}$ uso destes resíduos como componentes de substratos hortícolas propicia a obtenção de materiais alternativos de fácil e constante disponibilidade a baixo custo, minimizando a poluição decorrente de seu acúmulo no ambiente (SCHMITZ et al., 2002). Como exemplos de resíduos amplamente utilizados temse: estercos, farinha de peixe, farinha de osso, serragem, casca de pinus, casca de eucalipto, fibra de coco, cama de frango, casca de arroz carbonizada, bagaço de cana, etc.

Na região do Vale do Ribeira (SP), segundo a Associação dos Mineradores de Areia do Vale do Ribeira, a extração de areia de leito de rio gera mensalmente cerca de $800 \mathrm{~m}^{3}$ de resíduo fino de mineração de areia. Não há utilidade para esse material que atualmente é depositado em terrenos próximos ao local de processamento, ocupando a cada dia mais áreas que poderiam ser destinadas à agricultura ou à preservação ambiental. A obtenção de um material alternativo à disposição de produtores de mudas de pupunheira, de fácil e constante disponibilidade e de baixo custo, além de indicar um destino final à grande quantidade de resíduo de mineração de areia produzido, 
minimizaria a degradação decorrente do seu acúmulo no meio ambiente. Assim, este trabalho teve como objetivo avaliar o crescimento de mudas de pupunheira quando utilizado o resíduo fino de mineração de areia como componente de substratos.

\section{MATERIAL E MÉTODOS}

\section{Local do experimento}

$\mathrm{O}$ experimento foi conduzido entre setembro de 2007 e março de 2008 no Polo Regional de Desenvolvimento Sustentável dos Agronegócios do Vale do Ribeira da Agência Paulista de Tecnologia dos Agronegócios (APTA), no município de Pariquera-açu, SO, nas coordenadas $24^{\circ} 36^{\prime} 31^{\prime \prime} \mathrm{S}$ e $47^{\circ} 53^{\prime} 48^{\prime \prime} \mathrm{O}$, a 25 metros s.n.m. (sobre o nível do mar).

\section{Área experimental}

As mudas foram mantidas em condição de ambiente protegido, em estrutura de madeira de 2,80 $\mathrm{m}$ de pé direito, com $20 \mathrm{~m}$ de comprimento e $6 \mathrm{~m}$ de largura, coberta com tela promovendo $50 \%$ de sombreamento e sobreposta com filme de polietileno com espessura de $150 \mu \mathrm{m}$. O viveiro estava lateralmente envolto com o mesmo material da cobertura até a altura de $50 \mathrm{~cm}$ do nível do solo (saia). A parte interna do viveiro apresentava canaletas de amianto suspensas a $0,90 \mathrm{~m}$ do solo por toras de madeira formando bancadas e sobre elas foram colocadas bandejas de plástico para suporte e separação das mudas.

\section{Instalação, delineamento experimental e tratos culturais}

Para a obtenção de plântulas foram utilizadas sementes de pupunheiras originárias de Yurimáguas, Peru, semeadas em germinadores contendo areia e serragem, na proporção 1:1, em ambiente protegido. Após 118 dias da semeadura, apenas plântulas que não apresentavam espinhos (inermes) foram repicadas para sacos de polietileno preto de $8 \times 20 \mathrm{~cm}$ (volume de 1,1 L), preenchidos com os diferentes substratos (tratamentos). Cada recipiente recebeu uma plântula em estádio de uma folha bífida.

Os tratamentos foram compostos por quatro diferentes proporções volumétricas $(1 ; 3: 1$; $1: 1 ; 1: 3)$ de resíduo de mineração de areia (RA) e casca de arroz carbonizada (CA) e um substrato padrão recomendado por BOVI (1998a), como descrito abaixo:

Tratamento 1:

Sigla: 1RA

Substrato: Resíduo de areia

Tratamento 2:

Sigla: 3RA:1CA Proporção: 3:1

Substrato: Resíduo de areia : Casca de arroz carbonizado

Tratamento 3:

Sigla: 1RA:1CA Proporção: 1:1

Substrato: Resíduo de areia : Casca de arroz carbonizado

Tratamento 4:

Sigla: 1RA:3CA Proporção: 1:3

Substrato: Resíduo de areia : Casca de arroz carbonizado

Tratamento 5:

Sigla: 3LA:1EC Proporção: 3:1

Substrato: Latossolo Amarelo podzólico álico :

Esterco de búfalo Curtido

O delineamento experimental empregado foi o de blocos ao acaso, com cinco tratamentos, cinco repetições, contendo quatro mudas por parcela.

Os substratos de todos os tratamentos receberam adubação química antes de acondicionados nos sacos plásticos, sendo: $500 \mathrm{~g}$ de $\mathrm{P}_{2} \mathrm{O}_{5} \mathrm{~m}^{-3} \mathrm{e}$ $100 \mathrm{~g} \mathrm{de}_{2} \mathrm{O} \mathrm{m}^{-3}$, proveniente de superfosfato simples e cloreto de potássio, respectivamente. O latossolo amarelo podzólico álico utilizado no tratamento 3LA:1EC recebeu, 60 dias antes da implantação do experimento, 9,75 kg de calcário dolomítico (Poder Relativo de Neutralização Total de $67 \%$ ) por $\mathrm{m}^{3}$ de terra, para se igualar à saturação de bases $(\mathrm{V} \%)$ do resíduo de mineração (56 \%).

As mudas foram mantidas em condição de ambiente protegido com irrigação variando conforme as condições de temperatura e umidade do ambiente, de forma a evitar a ocorrência de déficit hídrico dos substratos. Realizaram-se análises fitossanitárias das mudas no Laboratório de Sanidade Vegetal e Animal daUPD de Registro-APTA para detecção de possíveis doenças. Efetuaram-se pulverizações quinzenais preventivas e curativas com fungicidas (Mancozeb e Tebuconazole) alternadamente, a partir de 48 dias do transplantio, quando se observaram sintomas da incidência de Colletotrichum spp. nas folhas. Após 75 dias do transplante, iniciou-se a adubação de cobertura utilizando-se sulfato de amônia como fonte, aplicando 
$0,8 \mathrm{~g}$ de nitrogênio por muda.

\section{Caracterização dos substratos}

O resíduo de areia utilizado foi oriundo do porto de areia "Porto Seguro" localizado às margens do Rio Ribeira de Iguape, município de Registro, SP. Esse resíduo encontrava-se de acordo com as normas da ABNT 10.000/2004, não apresentando teores de metais pesados ou de outro composto químico com valores acima dos recomendados, sendo classificado como Classe II B, ou seja, resíduo inerte não perigoso (Tabela 1), de acordo com análise realizada na Ecolabor Comercial Consultoria e Análises Ltda. em São Paulo. Foi realizada avaliação da taxa de colonização micorrízica no resíduo de mineração de areia no Laboratório de Análises Microbiológicas do Instituto Agronômico, Campinas, SP, seguindo o método de Gerdemann e Nicolson (1963) e de Jenkins (1964), não sendo observada a presença de fungos micorrízicos arbusculares. A análise granulométrica (Tabela 2) do resíduo de mineração de areia foi realizada no Centro de Pesquisa e Desenvolvimento de Solos e Recursos Ambientais do Instituto Agronômico, Campinas, SP, conforme método de Camargo et al. (1986).

As análises físicas e químicas dos substratos (Tabela 2) foram realizadas no Centro de Pesquisa e Desenvolvimento de Solos e Recursos Ambientais do Instituto Agronômico, Campinas, SP, de acordo com os métodos descritos na Instrução Normativa SDA N ${ }^{\circ}$ 17 de 21 de maio de 2007 e por Camargo et al. (1986),

TABELA 1: Análise granulométrica do resíduo de mineração de areia oriundo do porto de areia Porto Seguro situado às margens do Rio Ribeira de Iguape, Registro, SP.

TABLE 1: Particle size analysis of the residue of sand mining coming from the Porto Seguro port of sand situated on the banks of 'Ribeira de Iguape' river, Registro, São Paulo state.

\begin{tabular}{lcc}
\hline Classificação & $\begin{array}{c}\text { Diâmetro de } \\
\text { partícula }(\mathrm{mm})\end{array}$ & $\begin{array}{c}\text { Quantidade } \\
(\%)\end{array}$ \\
\hline Argila & $<0,002$ & 6 \\
Silte & $0,002-0,053$ & 15 \\
Areia muito fina & $0,053-0,105$ & 21 \\
Areia fina & $0,105-0,21$ & 33 \\
Areia média & $0,21-0,50$ & 16 \\
Areia grossa & $0,50-1,00$ & 7 \\
Areia muito grossa & $1,00-2,00$ & 2 \\
\hline
\end{tabular}

com modificação. Determinando-se o espaço poroso total (PT) por umidade de saturação do substrato, o espaço preenchido com água (capacidade de retenção de água e microporosidade) e a porosidade de aeração (macroporosidade) pela mesa de tensão, enquanto que para a análise granulométrica utilizou-se o método da pipeta.

\section{Avaliação do desenvolvimento vegetativo}

As respostas das mudas aos tratamentos foram avaliadas por meio de medições mensais do crescimento da parte aérea de quatro mudas por parcela, mensurando-se as seguintes variáveis: altura da planta, número de folhas funcionais e diâmetro do coleto na região do colo. As medidas de altura foram realizadas com régua, do solo até o ponto entre a flecha e a folha +1 (folha mais nova expandida); o diâmetro do colo foi medido com paquímetro no coleto da planta acima da superfície do solo; o número de folhas funcionais foi obtido pela contagem de folhas verdes completamente expandidas. A taxa de crescimento relativo (TCR) foi calculada de acordo com Radford (1967) por meio da equação: TCR $=\ln A 2-\ln A 1 /$ t2t1 cm.cm ${ }^{-1}$.mês, onde: A1 e A2 são os valores de duas medições sucessivas; t 1 e $\mathrm{t} 2$ são os meses decorridos entre as duas observações.

\section{Avaliação de trocas gasosas e dos valores SPAD}

Para a realização das medidas de trocas gasosas, utilizou-se Sistema Portátil de Medidas de Fotossíntese, IRGA (Infra Red Gas Analyser, Li 6400, Licor) e para os valores SPAD o clorofilômetro, equipamento SPAD - Meter (Soil and Plant Analysis Development) modelo SPAD-502, Minolta, Japão. Os valores SPAD se referem à intensidade da coloração verde das folhas, correlacionando significativamente com os teores de clorofila (MALAVOLTA et al., 1997). As mensurações foram realizadas em março de 2008, quando as mudas apresentavam 180 dias após a repicagem, utilizando-se apenas três das quatro plantas por parcela para que não excedesse o período de avaliação, entre $9 \mathrm{~h}$ e $10 \mathrm{~h} 30 \mathrm{~min}$, e não houvesse diferença de incidência de luz. Durante as medidas, a densidade de fluxo de fótons fotossintéticos (DFFF) incidido naturalmente no interior da casa de vegetação manteve-se em $330 \mu \mathrm{mol} \mathrm{m} \mathrm{m}^{-2} \mathrm{~s}^{-1}$. As medidas foram realizadas na porção mediana do folíolo localizado na parte média da segunda folha mais jovem completamente expandida (folha +2 ). As folhas se apresentavam na forma bífida. Durante as medidas a DFFF na câmara foi mantida a $900 \mu \mathrm{mol} \mathrm{m}{ }^{-2} \mathrm{~s}^{-1}$, e a temperatura do ar manteve-se em torno de $28^{\circ} \mathrm{C}$. 
TABELA 2: Características físicas e químicas dos tratamentos formados por diferentes proporções de resíduo de mineração de areia e casca de arroz carbonizada $(1 ; 1: 1 ; 1: 3 ; 3: 1)$ para substrato e um substrato padrão: $1=1$ resíduo de mineração de areia (RA); $2=3 \mathrm{RA}: 1$ casca de arroz carbonizada (CA); 3 = 1RA:1CA; 4 = 1RA:3CA; $5=3$ LA (latossolo amarelo podzólico álico) :1EC (esterco de búfalo curtido).

TABLE 2: Physical and chemical characteristics of treatments consisting of different proportions of residue of sand mining and carbonized rice husk $(1 ; 1: 1 ; 1: 3 ; 3: 1)$ and a standard substrate: 1 $=$ residue of sand mining (RA); $2=3 \mathrm{RA}: 1$ carbonized rice husk $(\mathrm{CA}) ; 3=1 \mathrm{RA}: 1 \mathrm{CA} ; \mathrm{T} 4=$ $1 \mathrm{RA}: 3 \mathrm{CA} ; 5=3$ LA (alic podzolic yellow latosol): $1 \mathrm{EC}$ (buffalo manure).

\begin{tabular}{lccccc}
\hline \multirow{2}{*}{ Características } & \multicolumn{5}{c}{ Tratamentos } \\
\cline { 2 - 6 } & 1 & 2 & 3 & 4 & 5 \\
\hline Densidade Seca $\left(\mathrm{kg} \cdot \mathrm{m}^{-3}\right)$ & 949,1 & 842,0 & 645,3 & 461,4 & 621,7 \\
Espaço poroso total $(\% \mathrm{v} / \mathrm{v})$ & 60,0 & 62,0 & 65,0 & 71,0 & 76,0 \\
CRA 10 (\% v/v) & 56,0 & 54,0 & 57,0 & 44,0 & 55,0 \\
Microporosidade (\% v/v) & 46,0 & 41,0 & 36,0 & 26,0 & 46,0 \\
Macroporosidade (\% v/v) & 14,0 & 21,0 & 30,0 & 44,0 & 30,0 \\
Argila (\%) & 6,08 & 6,73 & 6,67 & 6,95 & 48,75 \\
Silte (\%) & 15,34 & 16,31 & 18,02 & 18,03 & 31,48 \\
Areia total (\%) & 78,59 & 76,96 & 75,31 & 75,02 & 19,77 \\
PH & 5,6 & 5,6 & 6,0 & 6,6 & 5,4 \\
EC (mS.cm $\left.{ }^{-1}\right)$ & 0,6 & 0,6 & 0,7 & 0,7 & 2,1 \\
$\mathrm{C}_{\text {org }}(\%)$ & 2,65 & 8,91 & 15,18 & 22,14 & 11,95 \\
\hline
\end{tabular}

Em que: Método de extração: $\mathrm{pH}$ e condutividade elétrica $(\mathrm{CE})$ 1:2. Carbono orgânico $\left(\mathrm{C}_{\mathrm{org}}\right)$ : método de WalkleyBlack. Capacidade de retenção de água (CRA 10): mesa de tensão a $10 \mathrm{~cm}$ de coluna d'água (10 hPa). Microporosidade, macroporosidade (mesa de tensão a $60 \mathrm{~cm}$ de coluna d'água (60 hPa). Argila: diâmetro de partícula $<0,002 \mathrm{~mm}$; silte: entre 0,053-0,002 mm; areia total: $2,00-0,053 \mathrm{~mm}$.

\section{Análise estatística}

Para as variáveis relativas ao crescimento das mudas e trocas gasosas, foi efetuada análise de variância e comparação de médias pelo teste de Tukey a $5 \%$ de probabilidade.

\section{RESULTADOS E DISCUSSÃO}

Medidas lineares como altura e diâmetro do coleto são de natureza não destrutiva, facilmente avaliadas, e que apresentam correlação positiva e significativa com a produção de palmito (CLEMENT e BOVI, 2000).

Como pode ser observado na Figura 1A, os tratamentos que consistiam nas proporções $3: 1 ; 1: 1$ (RA:CA) e 3LA:1EC não apresentaram diferença significativa entre eles quanto ao diâmetro do coleto nas seis avaliações realizadas. As plantas do tratamento 1RA apresentaram diâmetro do coleto menor, significativamente distinto $(\mathrm{P} \leq 0,05)$ daquelas desenvolvidasnotratamento3LA:1EC, apartirdos 120 dias após a repicagem (DAR) até 180 DAR. Durante produção de mudas ocorre uma limitação de espaço para produção de raízes, resultado do confinamento em recipientes (saquinhos de polietileno). A limitação do volume exige que o substrato seja capaz de manter água facilmente disponível às plantas, sem que haja comprometimento de concentração de oxigênio no meio(FERMINO, 2002). A inferioridade do resultado do tratamento com resíduo de mineração de areia puro (1RA) deve-se, provavelmente, à presença de grande quantidade de partículas finas que se arranjam entre as mais grossas e formam poros de menor diâmetro o que, consequentemente, acarreta menor porosidade de aeração. Além disso, a densidade desse substrato é alta $\left(949,1 \mathrm{~kg} \cdot \mathrm{m}^{-3}\right)$ condizendo com a menor porosidade total desse material. Essas características físicas do substrato do tratamento 1RA podem ter afetado a respiração das raízes devido à redução da aeração, o que pode ter provocado problemas na absorção de nutrientes, afetando o crescimento das mudas. 
Na Figura 1B, a taxa de crescimento relativo (TCR) do diâmetro do coleto não apresentou diferenças significativas entre os tratamentos, exceto no período 150-180 DAR. A TCR do diâmetro do coleto apresentou no primeiro período avaliado (30-60 dias após a repicagem) valores superiores aos períodos subsequentes. Isso pode ter ocorrido porque as plantas, em geral, apresentam maior capacidade em produzir material novo por unidade pré-existente (LOPES et al., 2007; BARREIRO et al., 2006).

Quanto à variável altura da haste, podese verificar na Figura $2 \mathrm{~A}$ que houve diferença significativa, a partir dos 90 DAR até 180 DAR, entre as mudas formadas no tratamento 1RA, formado apenas com resíduo de mineração de areia, e aquelas produzidas no tratamento padrão (3LA:1EC). As plantas cultivadas no tratamento 1RA:3CA apresentaram nas avaliações realizadas entre 90 DAR e 120 DAR altura da haste significativamente inferior as dos tratamentos 3RA:1CA e 3LA:1EC. Porém, a partir dos 150 DAR até os 180 DAR houve acréscimo na taxa de crescimento relativo das plantas desse tratamento, fazendo com que estas alcançassem em altura da haste as plantas dos tratamentos 3RA:1CA,
1RA:1CA e 3LA:1EC. Embora a altura da haste seja uma medida linear correlacionada positivamente com produção de palmito, na produção de mudas, essa variável, isoladamente, pode não ser uma boa opção para a classificação de mudas. Os trabalhos que correlacionam essa variável com produção de palmito referem-se, em sua totalidade, ao cultivo em campo, após o transplante das mudas (BOVI et al., 1990; BOVI et al., 1991; BOVI et al., 1992; UZZO et al., 2002). Em condições de viveiro, devido ao adensamento a que as mudas são submetidas, existe uma competição por luz, o que pode causar um estiolamento das mudas, aumentando os valores de altura sem que isso acarrete em um benefício. Dessa forma, há necessidade de associar a altura da haste a outros parâmetros morfológicos de qualidade, como número de folhas e diâmetro do coleto.

A TCR pode ser considerada como um índice de eficiência, uma vez que representa em um determinado intervalo de tempo a capacidade de a planta produzir novos tecidos. Observando a Figura $2 \mathrm{~B}$, nota-se que essa taxa variou muito durante o período de realização deste trabalho. Verifica-se que o maior crescimento das plantas, ocorreu, de forma geral, no primeiro mês de avaliação, sendo que, nos meses seguintes, houve decréscimo na
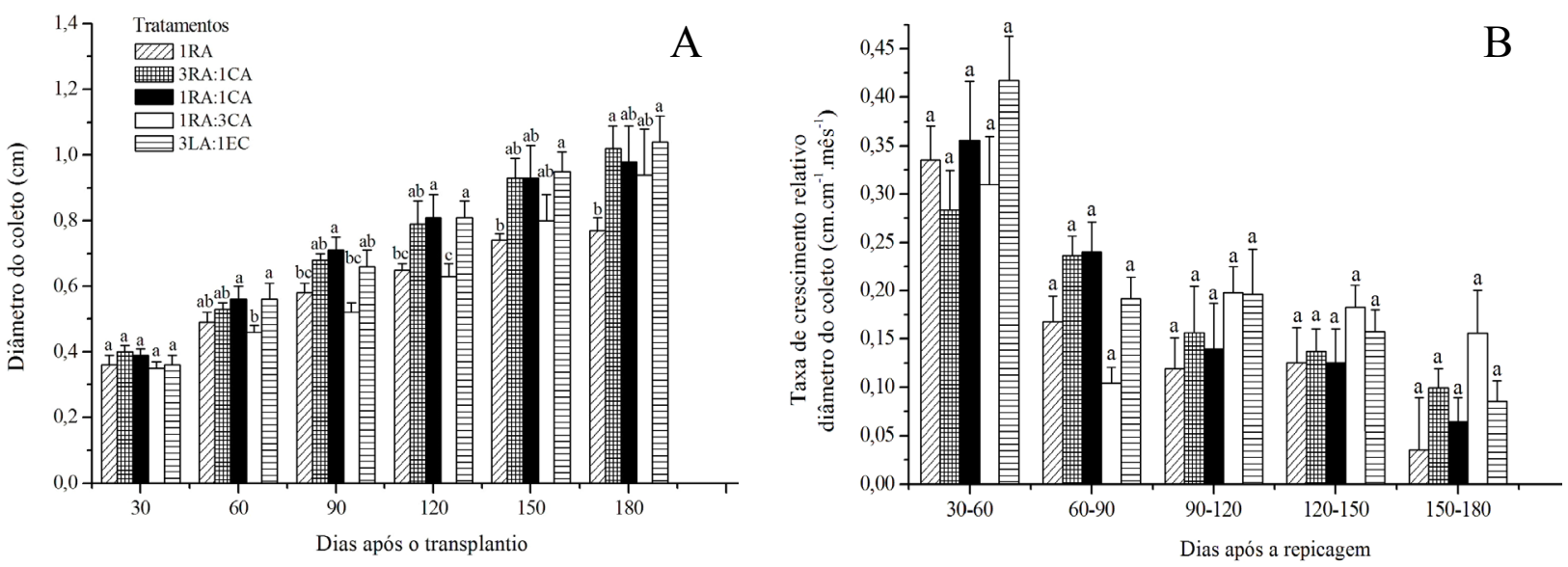

FIGURA 1: Diâmetro de coleto (A) e taxa de crescimento relativo (TCR) do diâmetro do coleto (B) de mudas de pupunheira cultivadas nos substratos dos tratamentos: 1RA; 3RA:1CA; 1RA:1CA; 1RA:3CA; 3LA:1EC, em Pariquera-açu, SP. Os resultados representam médias de 4 plantas e as barras o erro padrão. Médias seguidas da mesma letra, dentro do mesmo período (dias), não diferem significativamente pelo teste de Tukey a $5 \%$.

FIGURE 1: Stem diameter (A) and relative growth rate (RGR) of stem diameter (B) for pejibaye seedlings grown in substrates of treatments: 1RA; 3RA:1CA; 1RA:1CA; 1RA:3CA; 3LA:1EC, in Pariquera-açu (SP). Results represent means of 4 plants and bars, the standard error. Means followed by the same letter within the same period (days) do not differ significantly by Tukey test at $5 \%$. 
taxa. Isso também ocorreu em mudas de pupunheira observadas por Garcia e Fonseca (1991) e Previtalli (2007).

Para a variável número de folhas, constatou-se que não houve diferença significativa $(\mathrm{P} \leq 0,05)$ entre blocos, nem para os diferentes tratamentos (Figura 3) durante o período avaliado, exceto na terceira avaliação, quando os substratos dos tratamentos 3RA:1CA, 1RA:1CA e 3LA:1EC diferenciaram significativamente do tratamento 1RA:3CA.

Observando a Figura 3, no início do desenvolvimento das mudas houve aumento rápido no número de folhas, aos $90 \mathrm{DAR}$ a menor quantidade de folhas foi apresentada no tratamento 1RA:3CA, 2,0 folhas, e a maior no tratamento 3LA:1EC, 2,7 folhas. Nas avaliações subsequentes esse aumento passou a ter um ritmo mais lento, apresentando na avaliação final a média mínima de 2,87 folhas e máxima de 3,79 folhas.

Pode se observar que a quantidade de folhas das mudas de pupunheira após 180 DAR, para todos os tratamentos, foi abaixo das 6 folhas expandidas indicadas por Bovi (1998b) para se considerar uma muda pronta para ser transplantada no campo. Garcia e Fonseca (1991) observaram
5,92 folhas em mudas de pupunheiras produzidas em substrato formado por terriço de mata da parte superficial do solo adicionado adubado mineral, na avaliação feita aos 205 dias após a repicagem. Já Yuyama e Mesquita (2000) observaram, após 180 dias da repicagem, a presença de 5 folhas em mudas de pupunheira produzidas com o uso de esterco de galinha e latossolo na composição do substrato.

Muitas vezes, a redução do número de folhas da planta pode ser reflexo de condições desfavoráveis no ambiente radicular, já que isso pode provocar desequilíbrio fisiológico nas plantas em geral (LAUCHI e EPSTEIN, 1984; AYERS e WESTCOT, 1999). Contudo, o baixo número de folhas das mudas de pupunheira verificado na avaliação final do experimento, provavelmente ocorreu devido à incidência de doenças foliares observadas, principalmente nos últimos 30 dias do experimento. Sendo assim, neste experimento, esse parâmetro pode não ser satisfatório para mostrar as possíveis diferenças entre os tratamentos.

Quanto à assimilação de $\mathrm{CO}_{2}$ (Figura 4A), condutância estomática (Figura 4B) e transpiração (Figura 4C) das mudas de pupunheira não foram observadas diferenças significativas entre os tratamentos.
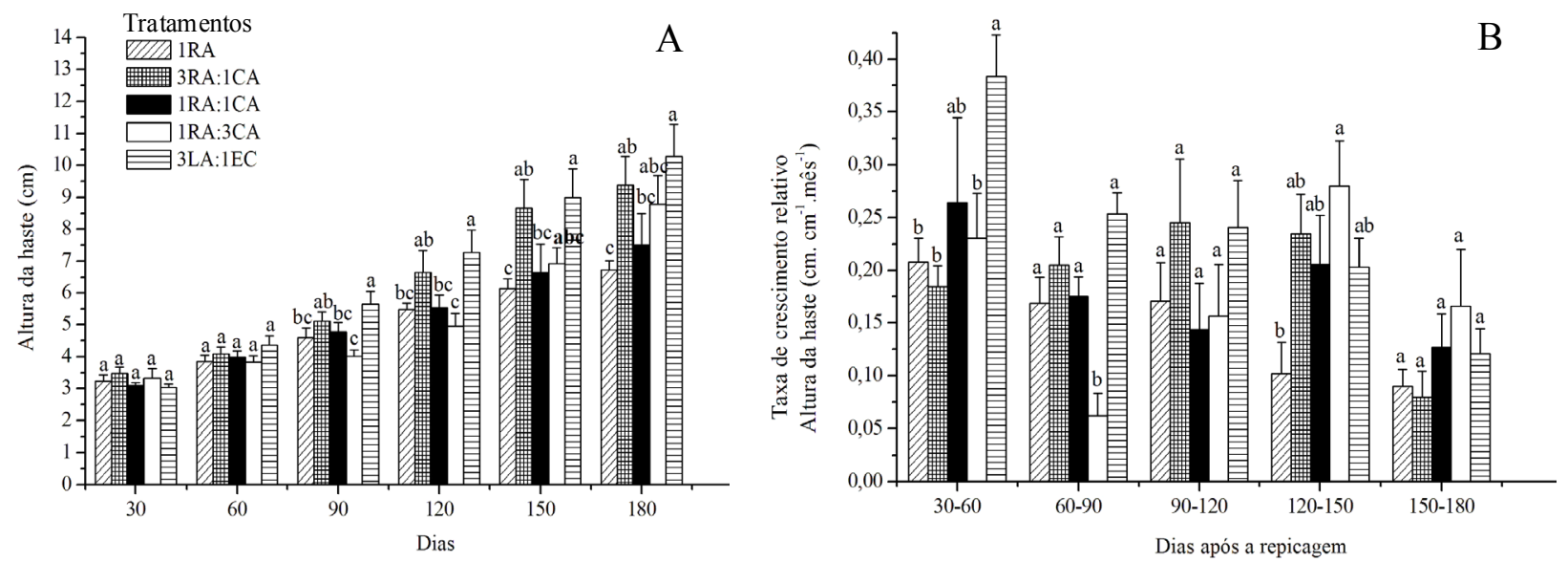

FIGURA 2: Altura da haste (A) e taxa de crescimento relativo (TCR) da altura da haste (B) de mudas de pupunheira cultivadas nos substratos dos seguintes tratamentos: 1RA; 3RA:1CA; 1RA:1 CA; 1RA:3CA; 3LA:1EC em Pariquera-açu, SP. Os resultados representam médias de 4 plantas e as barras o erro padrão. Médias seguidas da mesma letra, dentro do mesmo período (dias), não diferem significativamente pelo teste de Tukey a $5 \%$.

FIGURE 2: Plantlet height (A) and relative growth rate (RGR) of plantlet height (B) for pejibaye seedlings grown in substrates of treatments: 1RA; 3RA:1CA; 1RA:1CA; 1RA:3CA; 3LA:1EC, in Pariquera-açu, São Paulo state. Results represent means of 4 plants and bars, the standard error. Means followed by the same letter within the same period (days) do not differ significantly by Tukey test at $5 \%$. 
$\mathrm{O}$ maior valor médio da assimilação de $\mathrm{CO}_{2}$ foi encontrado nas mudas do tratamento 3LA:1EC de $5,4 \mu \mathrm{mol} \cdot \mathrm{m}^{-2} \cdot \mathrm{s}^{-2}$, seguido pelo do tratamento 1RA:3CA $\left(5,0 \mu \mathrm{mol} . \mathrm{m}^{-2} . \mathrm{s}^{-2}\right)$, sendo esses valores mais baixos que a média de $10,1 \mu \mathrm{mol} \cdot \mathrm{m}^{-2} \cdot \mathrm{s}^{-2}$ observados por Oliveira et al. (2002) para mudas de pupunheiras com 12 meses de idade e submetidas à iluminação com densidade de fluxo de fótons fotossinteticamente ativos (DFFFA) de $1200 \mu \mathrm{mol}$ $\mathrm{m}^{-2} \mathrm{~s}^{-1}$.

Ainda na Figura 4, observa-se que o padrão de valores da condutância estomática seguiu aquele apresentado pela transpiração. Para as trocas gasosas observou-se grande variabilidade entre plantas, o que era esperado. Essa variação entre plantas para trocas gasosas, já tinha anteriormente sido descrita por Tucci et al. (2006).

Quanto à eficiência do uso da água (assimilação de $\mathrm{CO}_{2}$ /transpiração) também não houve diferença significativa entre os tratamentos (dados não apresentados), o que demonstra que mesmo as mudas submetidas ao tratamento 1RA, com resíduo de areia puro, não apresentaram suas trocas gasosas comprometidas.

Os valores SPAD das plantas desenvolvidas no substrato do tratamento 3LA:1EC, correspondente ao considerado padrão, diferiram significativamente dos demais $(\mathrm{P} \leq 0,05)$. Vários autores observaram em diversas espécies correlações entre os valores SPAD e os teores de clorofila e nitrogênio das folhas (TUCCI, 2004). De acordo com Previtalli (2007), a variação dos valores SPAD encontrados em mudas de pupunheira em dois tipos de substratos diferentes estiveram relacionados à condição nutricional proporcionada por eles, o que pode explicar a superioridade dos valores SPAD encontrados nas mudas do tratamento 3LA:1EC, único com esterco de búfalo curtido em sua composição. Assim, estudos adicionais devem ser realizados sobre a adição de nutrientes minerais na formulação de substratos compostos por resíduo de areia e casca de arroz.

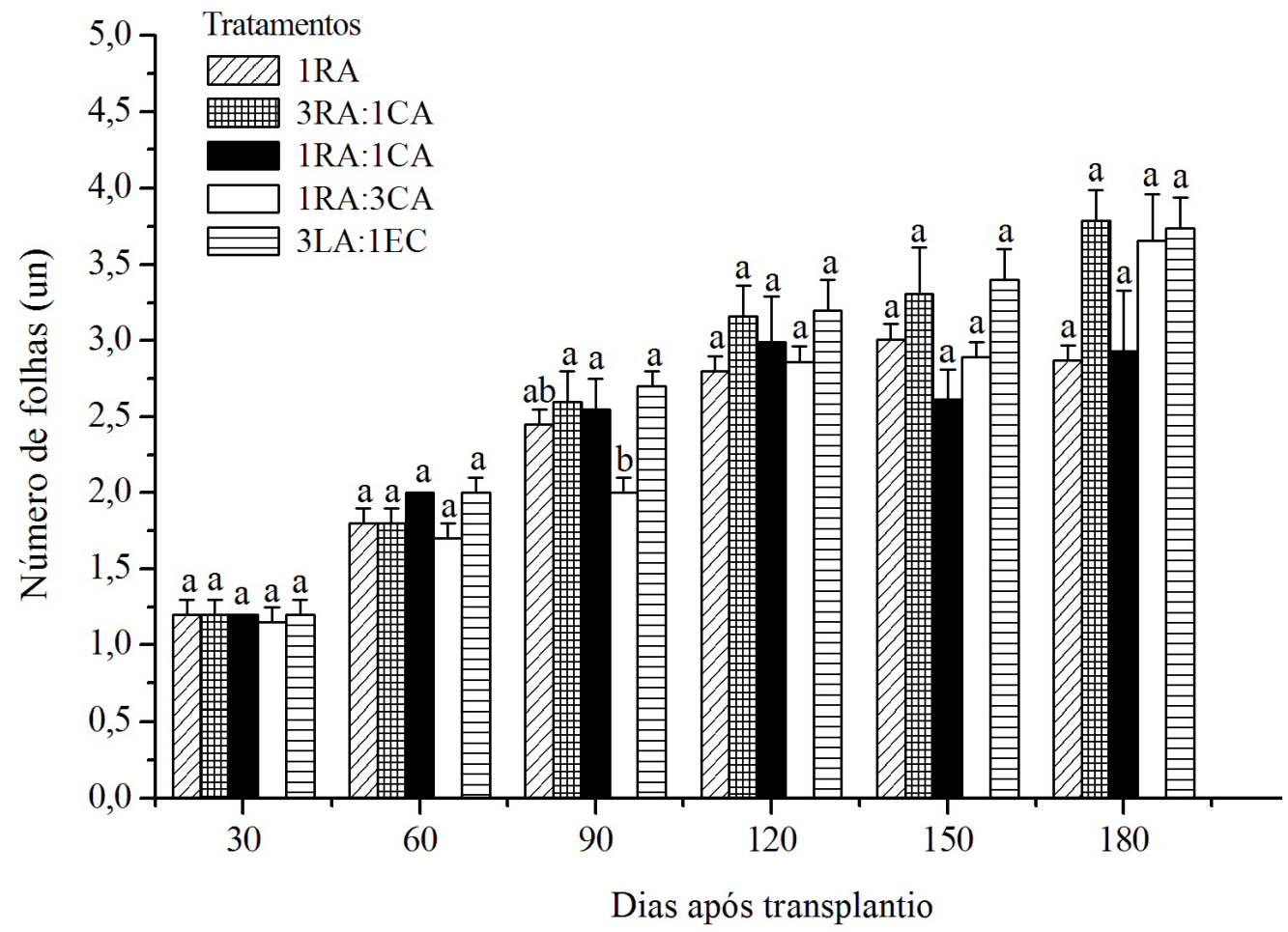

FIGURA 3: Número de folhas de mudas de pupunheira cultivadas nos substratos dos seguintes tratamentos: 1RA; 3RA:1CA; 1RA:1CA; 1RA:3CA; 3LA:1EC, em Pariquera-açu, SP. Os resultados representam médias de 4 plantas e as barras o erro padrão. Médias seguidas da mesma letra, dentro do mesmo período (dias), não diferem significativamente pelo teste de Tukey a $5 \%$.

FIGURE 3: Number of leaves for pejibaye seedlings grown in substrates of the following treatments: 1RA; 3RA:1CA; 1RA:1CA; 1RA:3CA; 3LA:1EC, in Pariquera-açu, São Paulo state. Results represent means of 4 plants and bars, the standard error. Means followed by the same letter within the same period (days) do not differ significantly by Tukey test at $5 \%$. 

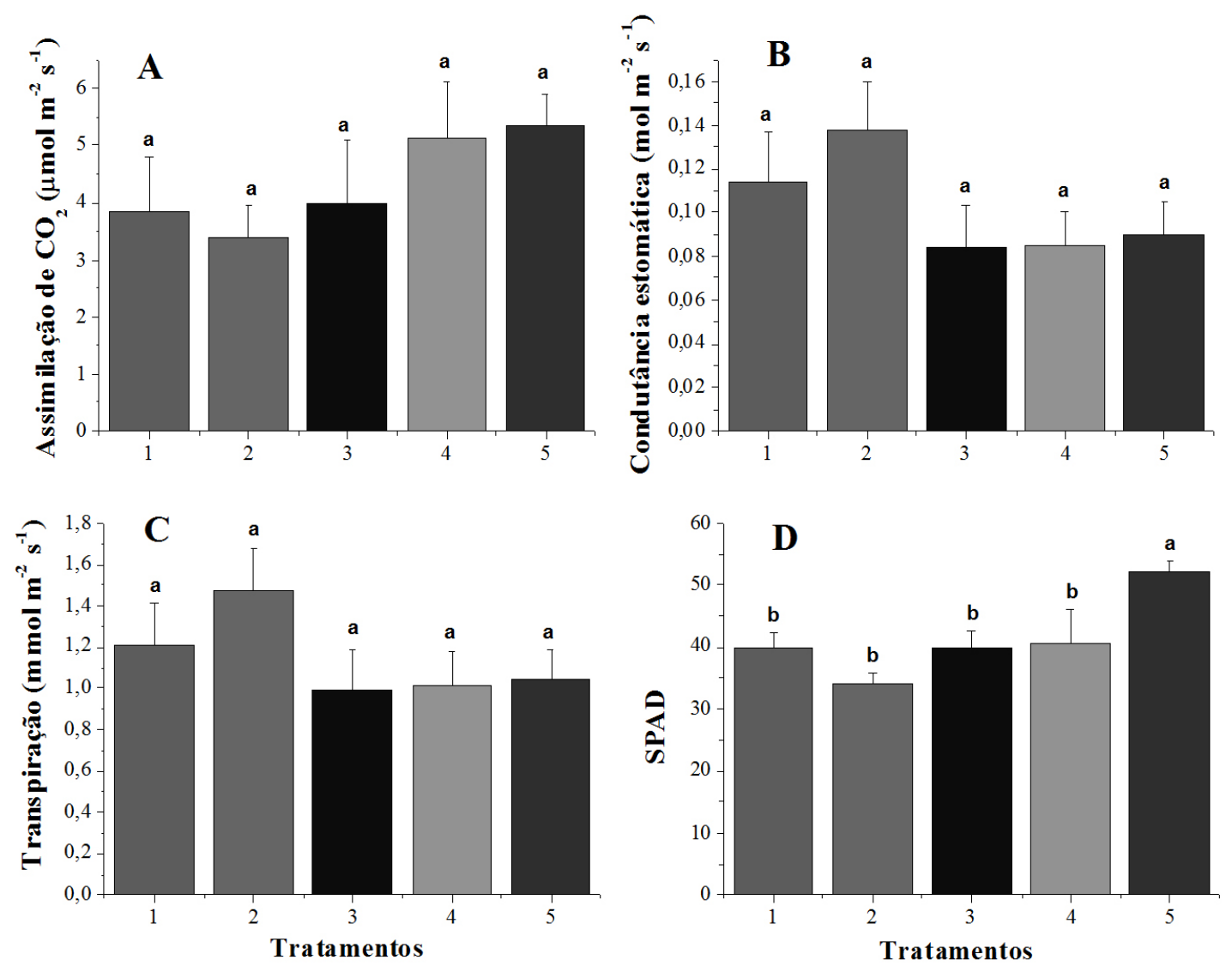

FIGURA 4: Valores de assimilação de $\mathrm{CO}_{2}(\mathrm{~A})$, condutância estomática (B), transpiração (C) e unidades SPAD (D) de folhas de mudas de pupunheira 180 dias após a repicagem, cultivadas nos substratos: $1=1 \mathrm{RA} ; 2=3 \mathrm{RA}: 1 \mathrm{CA} ; 3=1 \mathrm{RA}: 1 \mathrm{CA} ; 4=1 \mathrm{RA}: 3 \mathrm{CA} ; 5=3 \mathrm{LA}: 1 \mathrm{EC}$, em Pariquera-açu, SP, 2008. Os resultados representam médias de 3 plantas e as barras o erro padrão. Médias seguidas de letras iguais na coluna são consideradas estatisticamente iguais ao nível de $5 \%$ de probabilidade pelo teste de Tukey.

FIGURE 4: $\mathrm{CO}_{2}$ assimilation values (A), stomatal conductance (B), transpiration rate (C) and SPAD (Soil Plant Analysis Development) values (D) on leaves of pejibaye seedlings 180 days after the transplanting to bags, grown in substrates of the following treatments: 1RA; 3RA:1CA; 1RA:1CA; 1RA:3CA; 3LA:1EC, in Pariquera-açu, São Paulo state. Results represent means of 3 plants and bars, the standard error. Means followed by the same letter within the same period (days) do not differ significantly by Tukey test at $5 \%$.

\section{CONCLUSÃO}

Com base nos resultados obtidos pode-se concluir que:

- O substrato composto apenas por resíduo de mineração de areia não propiciou mudas adequadas para transplante em local definitivo, devido às baixas taxas de crescimento.

- Para produção de mudas de pupunheira, o resíduo de mineração de areia pode ser utilizado na composição de substratos, desde que agregado a outros materiais.
- Os valores SPAD mais altos das folhas das mudas produzidas no substrato padrão em relação aos demais indicam a necessidade de suplementação mineral na formação das mudas de pupunheira formadas em substratos compostos por proporções entre resíduo de areia e casca de arroz.

\section{AGRADECIMENTOS}

À Associação dos Mineradores de Areia do Vale do Ribeira e Baixada Santista, SP. 


\section{REFERÊNCIAS BIBLIOGRÁFICAS}

ABAD, M. Los sustratos hortícolas y técnicas de cultivo sin suelo. In: RALLO, L.; NUEZ, F. La horticultura Española en la C.E, Réus: Horticultura S.L., p.271-280, 1991.

ABOBOREIRANETO, M. Pupunheira. Disponível em: $\quad<$ (http://www.ceplac.gov.br/radar/Artigos/ artigo24.htm) > Acesso em: 08 de março de 2009.

ANEFALOS, L. C; TUCCI, M. L. S; MODOLO, V. A. Uma visão sobre a pupunheira no contexto do mercado de palmito. Análises e Indicadores do Agronegócio, v. 2, n. 7, 2007.

AYERS, R. S.; WESTCOT. D. W. A qualidade de água na agricultura. Campina Grande: Universidade Federal da Paraíba, 1999. 53 p. (FAO Irrigation Drainage Daper, 29)

BACKES, M. A.; KÄMPF, A. N. Substrato a base de composto de lixo urbano para a produção de plantas ornamentais. Pesquisa Agropecuária Brasileira, v. 26. n. 5, p. 753-758, 1991.

BARREIRO, A. P. et al. Análise de crescimento de plantas de manjericão tratadas Com reguladores vegetais. Bragantia, Campinas, v. 65 , n. 4 , p. 563 567, 2006.

BOVI, M. L. A. et al. Relação entre alguns caracteres da planta e do palmito de açaizeiros (Euterpe oleracea). Bragantia, Campinas, v. 49, n. 01, p. 6981, 1990.

BOVI, M. L. A. Expansão do cultivo da pupunheira para palmito no Brasil. Horticultura Brasileira, Brasília, v. 15, p. 183- 185, 1998a. supl.

BOVI, M. L. A. Palmito pupunha: informações básicas para cultivo. Campinas: Instituto Agronômico, 1998b. (Boletim técnico, n. 173)

BOVI, M. L. A.; GODOY JÚNIOR, G.; SAES, L. A. Correlações fenotípicas entre caracteres da palmeira Euterpe edulis Mart. e produção de palmito. Revista Brasileira de Genética, v. 14, n. 1, p. 105-121, 1991.

BOVI, M. L. A.; GODOY JUNIOR, G.; SPIERING, S. H. Respostas de crescimento da pupunheira à adubação NPK. Scientia Agricola, v. 59, n. 1, p. 161-166, 2002.

BOVI, M. L. A.; SAES, L. A.; GODOY JÚNIOR, G. Correlacões fenotipicas entre caracteres não destrutíveis e palmito em pupunheiras. Revista Turrialba, San José, v. 42, n. 3, p. 382-390, 1992.

CAMARGO, O.A. et al. Métodos de análise química, mineralógica e física de solos do IAC.
Campinas: Instituto Agronômico de Campinas, 1986. (IAC Publicação 106).

CLEMENT, C. R.; BOVI, M. L. A. Padronização de medidas de crescimento e produção em experimento com pupunheiras para palmito. Acta Amazonica, v. 30, n. 3, p. 349-362, 2000.

COSTA, M. C. et al. Substratos para produção de mudas de jenipapo (Genipa americana L.). Pesquisa Agropecuária Tropical, Goiânia, v. 35, n. 1, p. 1924, 2005.

FERMINO, M. H. O uso da análise física na avaliação da qualidade de componentes e substratos. In: ENCONTRO NACIONAL DE SUBSTRATOS PARA PLANTAS, 2., 2002, Campinas. Anais... Campinas: IAC, 2002, p. 29-37.

GARCIA, T. B.; FONSECA, C. E. L. Crescimento de mudas de pupunheira em condições de viveiro coberto com palha. Pesquisa Agropecuária Brasileira, Brasília, v. 26, n. 9, p. 1447-1451, 1991. GERDEMANN, J. W.; NICOLSON, T. H. Spores of mycorrhizal Endogone species extracted from soil by wet sieving and decanting. Transactios of the British Mycological Society, London, v. 46, p. 235246, 1963.

GUERRERO, F.; POLO, A. Control de las propriedades hidrofísicas de las turbas para su utilización agrícola. Agricoltura Mediterrânea, v. 119, p. 453-459, 1989.

JENKINS, W. R. A rapid centrifugal-flotation technique for separating nematoides from soil. Plant Disease Reporter, Beltsville, v. 48, n. 9, p. 692, 1964.

LAUCHI, A.; EPSTEIN, E. Mechanisms of salt tolerance for plants. California Agriculture, Oakland, v. 38, n. 10, p. 18-20. 1984.

LOPES, J. L. W. et al. Crescimento de mudas de alface em diferentes substratos. Biotemas, v. 20, n. 4, p. 19-25, 2007.

LUPA - LEVANTAMENTO CENSITÁRIO DE UNIDADES DE PRODUÇÃO AGRÍCOLA DO ESTADO DE SÃO PAULO. Atualização 2008. Disponível em: <(http:॥www.cati.sp.gov.br)> Acesso em: 15 de julho de 2009.

MALAVOLTA, E.; VITTI, G. C.; OLIVEIRA, S. A. Avaliação do estado nutricional das plantasprincípios e aplicações. 2. ed., Piracicaba: Potafós, 1997. $319 \mathrm{p}$.

MINAMI, K. Produção de mudas de alta qualidade em horticultura. São Paulo: T.A. Queiroz, 1995.136 p.

OLIVEIRA, M. A. J. et al. Fotossíntese, condutância estomática e transpiração em pupunheira sob 
deficiência hídrica. Scientia Agrícola, v. 59, p. 5963, 2002.

PREVITALLI, R. von Z. Crescimento de mudas de pupunheira (Bactris gasipaes Kunth) em substrato compactado. 2007. 101 f. Dissertação (Mestrado em Agricultura Tropical) - Instituto Agronômico, Campinas, 2007.

RADFORD, P. J. Growth analysis formulae - their use and abuse. Crop Science, v. 7, n. 3, p. 171-175, 1967.

SCHMITZ, J. A. K.; SOUZA, P. V. D.; KAMPF, A. N. Propriedades químicas e físicas de substratos de origem mineral e orgânica para o cultivo de mudas em recipientes. Ciência Rural, Santa Maria, v. 32, n. 6, p. 937-944. 2002.

SOUZA, R. J.; FERREIRA, A. Produção de mudas de hortaliças em bandejas: economia de sementes e defensivos. A Lavoura, Rio de Janeiro, n. 623, p. 19-21, 1997.
TUCCI, M. L. S. Variação estacional do crescimento e de trocas gasosas em pupunheira (Bactris gasipaes Kunth). 2004. 180 f. Tese (Doutorado) - Universidade Estadual de Campinas, Campinas, 2004.

TUCCI, M. L. S.; MACHADO, E. C.; BOVI, M. L. A. Variabilidade fenotípica de trocas gasosas em pupunheiras. In: CONGRESSO BRASILEIRO DE OLERICULTURA, 46., 2006, Goiânia. Anais... Goiânia: UFG, 2006, 1 CD-ROM.

UZZO, R. P. et al. Correlações fenotípicas entre caracteres vegetativos e de produção de palmtio da palmeira real australiana. Scientia Agricola, Piracicaba, v. 59, n. 3, p. 505-511, 2002.

YUYAMA, K.; MESQUITA, S. M. S. Crescimento de mudas de pupunheira (Bactris gasipaes) transplantadas em diferentes estádios de plântula, substratos e volume de substrato. Acta Amazonica, Manaus, v. 30, n. 3, p. 515-520. 2000. 